\title{
O pensamento bergsoniano para uma teoria dos estudos das teleaudiovisualidades
}

\author{
Ana Cláudia de Cruz Melo' \\ https://orcid.org/0000-0001-7508-6345 \\ I - UFPA \\ Belém (PA), Brasil.
}

KILPP, S. Imagem-duração e

teleaudiovisualidades na internet.

Curitiba: Appris, 2018. 153 p.

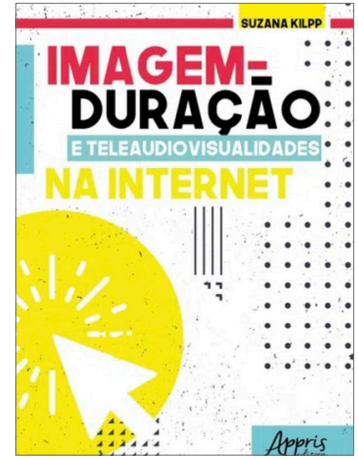

Resumo: O livro Imagem-duração e teleaudiovisualidades na internet oferece aos estudiosos das problemáticas advindas dos campos televisivo e audiovisual não apenas um profícuo encontro com reflexões inspiradas pelo pensamento bergsoniano aplicado às relações da televisão com o tempo ou o tempo na TV. A publicação oferece sobretudo outras perspectivas epistemológicas às investigações acerca de possíveis construtos televisivos de tempo enquanto territórios de experiências e de significações, especialmente, pós-internet ou mais especificamente, quando a Web abre novas possibilidades à TV.

Palavras-chave: televisão; tempo na TV; imagem-duração; teleaudiovisualidades; tele-audiovisão.

Abstract: The bergsonian thought for a theory and teleaudiovisualities studies - The book Imagem duração e teleaudiovisualidades na internet ("Image-duration and teleaudiovisualities on the internet") offers to scholars of the problematic coming from the televising and audiovisual fields not only a fruitful encounter with reflections inspired by the bergsonian thought applied to the relations of the television with the time or the time on TV. The publication mainly offers other epistemological perspectives to investigations of possible television constructs of time as territories of experiences and meanings, especially post-internet ones or more specifically when the Web opens new possibilities to the TV.

Keywords: television; time on TV; image - duration; teleaudiovisualities; tele-audiovision. 
Às vésperas da televisão brasileira completar 70 anos de existência, o livro Imagemduração e teleaudiovisualidades na internet, de autoria da pesquisadora Suzana Killp (2018), possibilita novas compreensões sobre o que vem se tornando a tevê nos dias de hoje. Para isso, traz a hipótese "de a mídia TV (off-line) ser apenas uma das atualizações possíveis de uma virtualidade mais larga", a qual chama de "tele-audiovisão", sendo inclusive, não apenas as TV's off-line, mas também as TV's on-line e as web TV's "pensadas como atualizações (diferentes entre si apenas em grau) da tele-audiovisão durante" (KILPP, 2018, p. 132).

O conceito de tele-audiovisão é apresentado como um dos principais resultados da pesquisa na qual Kilpp dedica-se a problematizar a duração (temporal) da imagem audiovisual de tevê, investigação que a levou a propor, inicialmente, o conceito de imagem-duração como sendo a imagem televisiva do tempo - "a imagem desenrolandose na TV em um tempo também se desenrolando" (2018, p. 15). Nesta etapa atual, sua compreensão fundamenta-se na constatação de que a imagem-duração, considerada ainda como precípua da TV off-line, entra em crise quando e enquanto as emissoras ensaiavam/ ensaiam e experimentavam/experimentam estender conteúdos de seus programas para um público amplo e genérico, e ao mesmo tempo, específico. Kilpp, antes, defendia a ideia de que a natureza singular das audiovisualidades de TV relacionava-se à imagemduração como uma imagem televisiva do tempo, virtualidade que se atualizava pela TV no fluxo da programação e no zapping e que, na televisão, realizava-se, antes de tudo, nos tempos que se dedica à sua assistência, tempos que raramente são sincrônicos ao tempo dos programas ou dos anúncios (KILPP, 2007, p. 32). Atualmente, Kilpp amplia essa noção para explicar os fenômenos que estão em curso: "a convergência e a dispersão de conteúdos televisivos (e de outros audiovisuais) na internet e, via ela, nos dispositivos móveis" (KILPP, 2018, p. 133). Assim, a pesquisadora traz, neste novo livro, a noção de tele-audiovisão como uma alternativa para investigar os entrelaçamentos dos vídeos na internet, que muitas vezes, na origem, são fragmentos audiovisuais de outras mídias, especialmente, a TV e o Cinema. Também levanta a hipótese de que a TV (e sua imagemduração) possa ser compreendida, portanto, como uma das atualizações dessa virtualidade mais larga, a tele-audiovisão (KILPP, 2018, p. 132). A pesquisadora apresenta, inclusive, o termo tele-audiovisão como aquele que poderia dar conta do protagonismo do som nas imagens televisivas. Nesse sentido, defende que as visualidades televisivas há tempo já deveriam ser compreendidas como áudio-visualidades, uma vez que em muitos casos, a parte audível das imagens acaba por ser preponderante nas narrativas e nos sentidos dos conteúdos televisivos.

Com esse novo livro, a pesquisadora também permite ao leitor revisitar ou conhecer a sua trajetória de investigações sobre a televisão brasileira. Estudos que Kilpp realiza desde o início dos anos 2000, que fundamentam a teoria que propõe acerca das audiovisualidades nas mídias e a colocam na direção de preencher uma lacuna no âmbito das Teorias da Comunicação, quando se trata de uma epistemologia do audiovisual pós-cinema. 
Afinal, diferentemente do que aconteceu com o Cinema, que tão logo surgiu, no final do século XIX, inúmeros intelectuais buscaram compreendê-lo à luz de múltiplas tradições teóricas - filosofia da arte, formativa, realista, semiológica, fenomenológico (ANDREW, 2002) -, a televisão, especialmente, no Brasil, foi investigada muito mais à luz da Teoria Crítica Social ou com foco no seu caráter funcionalista. As teorizações de Kilpp, nos últimos anos, ampliam esse horizonte teórico ao problematizar as práticas televisivas segundo a noção de tempo. Uma trajetória inspirada pelo pensamento do filósofo HenriLouis Bergson (1859-1941), no que tange a utilização da intuição como método e aos conceitos de duração e memória.

No primeiro capítulo, intitulado Das Imagens de TV à Imagem-Duração, Kilpp revisa como gradativamente foi levada à noção de imagem-duração. Explica que o seu esforço fundamenta-se em Bergson e nas regras sistematizadas por Deleuze quando escreve o livro Bergsonismo. Entre as quais, a terceira regra que trata de "colocar os problemas e resolvê-los mais em função do tempo do que espaço" e que consiste em pensar a intuição como duração. (DELEUZE, 2012, p. 24). Duração, que em A evolução Criadora, Bergson explica como o "progresso contínuo do passado que rói o futuro e que incha avançando" (BERGSON, 2010, p. 19). Deleuze pontua esse processo como sendo a "experiência ampliada" e não apenas "a experiência vivida", que "propicia sempre um misto de espaço e de duração", que tem como características fundamentais a "continuidade e a heterogeneidade" (DELEUZE, 2012, p. 31). Kilpp apropria-se desta forma de compreender a intuição aplicada às audiovisualidades, afirmando que, como um método, proporciona um olhar múltiplo e complexo para os fenômenos contemporâneos tecnoculturais relacionados à expansão do audiovisual nas mídias porque "acura explicações" e ao mesmo tempo permite "ensaiar a adoção de conceitos" (KILPP, 2018, p. 19) para uma análise mais pertinente de processos de significação nas mídias, que na atualidade são fortemente impactados pela convergência de tecnologias, formatos, linguagem e estéticas audiovisuais. Com esta perspectiva, a autora explica que buscou nos seus estudos responder à questão "em que formas se atualizam os devires audiovisuais que hoje se encontram na TV?". Propondo que essas formas fossem, primeiro, compreendidas como "instantâneos tomados de uma transição, ou como diferentes atualizações de uma mesma duração" (KILPP, 2018, p. 21).

A autora detalha ainda estar menos interessada na natureza da imagem audiovisual na web e muito mais nos modos como a tevê ensaiou na rede sua digitalização. Depois disso, da primeira a sexta parte do livro, retoma suas principais temáticas, problematizacões e/ou marcos conceituais - panoramas televisivos, molduras e moldurações, ethicidade, tempo reality, imagens-lembranças são alguns deles. Para assim, problematizar inclusive o abalo que a sua compreensão de imagem-duração "sofreu" quando os conteúdos televisivos passaram a migrar para a internet e, via ela, nos dispositivos móveis.

Contudo, mais do que uma revisão, a pesquisadora traz novos questionamentos acerca da tevê na internet. Por exemplo: a) O que distingue as TVs na internet das TVs 
off-line? b) O que distingue, na internet, as TVs on-line das webs TVs, umas das outras e das TVs off-line? c) O que há de comum, vitualmente falando, entre elas? Como e em que as semelhanças e diferenças impactam sobre o que se tem concertado acerca da tele-audiovisão como televisão? (KILPP, 2018, p. 136).

No capítulo conclusivo, Kilpp trata apenas da primeira questão - O que distingue as TVs na internet das TVs off-line? - Explicando que as demais serão "inexoravelmente" remetidas a novos projetos de pesquisa. Suas reflexões, nesse capítulo, se voltam às compreensões das imagens do tempo na tevê e de imagem-duração, pós-internet e o on-line. Conduz o leitor por reflexões acerca dos fluxos temporais distintos e que se justapõem no desenrolar do tempo da programação das emissoras. Afirma que "esses fluxos se desenrolando simultaneamente na macromontagem televisiva" lembram "por demais a noção bergsoniana de duração, na qual o tempo tem múltiplas direções" em que "tudo é presente coalescente". Razão pela qual, explica chamar o construto televisivo de imagem-duração, compreendida, assim, por ser "uma ethicidade que participa de um conjunto de enunciações televisivas sobre o real, o qual é, também, um construto de real (uma ethicidade) performático - um real reality". (KILPP, 2018, p. 139-140).

Tendo como sistema de referência o relógio digital presente nas telas da TV on-line a exemplo do que já havia analisado em relação a TV-off-line e nas transmissões "ao vivo" em 2003 -, Kilpp então passa a analisar os modos de transição operados pelas emissoras, quando apresentavam conteúdos audiovisuais na internet. Uma das suas conclusões é que as emissoras do corpus estudado ainda não seguem padrão para a disposição dos conteúdos - o que tornariam, por ora, as tevês on-line territórios de experimentação das emissoras acerca da sua refundação como digital. Com base na observação da apresentação do relógio nas transmissões simultâneas na internet, do relógio écran das imagens de arquivo e do próprio "grafhic ao vivo", analisa que atualmente "há uma liquefação de todos os sentidos e figurações de tempo como os temos entendido até hoje em sociedade" (KILPP, 2018, p. 146). Para uma sociedade, como a brasileira, em que as pessoas passam horas por dia assistindo televisão, e que cada vez mais o audiovisual torna-se central na internet, essa constatação e outras reflexões de Kilpp sobre as audiovisualidades tornamse, no mínimo, ainda mais instigantes para uma compreensão mais larga de duração (a tele-audiovisão) da mídia tevê, com a internet.

Ana Claudia Melo é É professora-adjunta de Teoria, História e Estética do curso de Cinema e Audiovisual da Faculdade de Artes Visuais do Instituto de Ciências da Arte (ICA) da Universidade Federal do Pará (UFPA). É doutora em Comunicação e Semiótica pela PUC-SP, mestra em Ciências da Comunicação e especialista em Cinema pela Unisinos/RS.

acmelo@ufpa.br 


\section{Referências}

ANDREW, D. As principais teorias do cinema. Rio de Janeiro: Zahar, 2002.

BERGSON, H. A Evolução Criadora. São Paulo: Ed. UNESP, 2010. 408p.

DELEUZE, G. Bergsonismo. São Paulo: Editora 34, 2012. (2ª Edição) 160 p.

KILPP, S. Novas figuras do tempo na televisão. Revista FAMECOS (Impresso), v. 34, p. 29-36, 2007.

Resenha recebida em 01/04/2020

e aprovada em 20/4/2020. 